Research Article

\title{
Modeling and Optimization of BT and DBT Photooxidation over Multiwall Carbon Nanotube-Titania Composite by Response Surface Methodology
}

\author{
Molood Barmala ${ }^{1}{ }^{1}$ and Mohammad Behnood ${ }^{2}$ \\ ${ }^{1}$ Department of Chemical Engineering, Dezful Branch, Islamic Azad University, Dezful, Iran \\ ${ }^{2}$ Department of Petroleum and Chemical Engineering, Science and Research Branch, Islamic Azad University, Tehran, Iran \\ Correspondence should be addressed to Molood Barmala; m.barmala@iaud.ac.ir
}

Received 30 October 2017; Revised 31 January 2018; Accepted 21 February 2018; Published 22 April 2018

Academic Editor: Alberto Álvarez-Gallegos

Copyright ( $) 2018$ Molood Barmala and Mohammad Behnood. This is an open access article distributed under the Creative Commons Attribution License, which permits unrestricted use, distribution, and reproduction in any medium, provided the original work is properly cited.

\begin{abstract}
This study investigates optimization of benzothiophene (BT) and dibenzothiophene (DBT) removal via a photocatalytic process by using central composite design (CCD) method. Temperature, $\mathrm{pH}$, and $\mathrm{p}-25$ to $\mathrm{MWCNT}$ ratio $(\mathrm{g} / \mathrm{g})$ in the composite structure are considered as design factors. According to the results, temperature has the greatest impact on removal rate. In optimal condition, after being exposed to UV lamps ( $9 \mathrm{~W}$ ) for $20 \mathrm{~min}, 59.8 \%$ of the solutions' BT was removed, while DBT was completely removed. Although the generated structure band gap is 3.4, but due to the presence of MWCNTs in the structure, it is capable of absorbing visible light, and this leads to complete removal of DBT and $42 \%$ removal of BT under visible light radiation (in similar circumstances). Kinetics analysis of thiophene's reaction showed that, in the presence of visible light, first order removal rate constants for DBT and BT are 7.98 and 0.953 1/h, respectively.
\end{abstract}

\section{Introduction}

With dramatic growth of petrochemical and automotive industries, air pollution caused by sulfur dioxide has become one of the major global problems. Since 2006, America Environmental Protection Agency announced that permitted concentrations of sulfur in diesel fuels should be below $15 \mathrm{ppm}$ [1-4].

Hydrogen desulfurization is considered as a common process for sulfur removal. The process requires large amounts of hydrogen and huge reactors [4-6]. Unfortunately, hydrogen process cannot remove thiophene and its derivatives which exist in heavy oil compounds $[1,2,4,6,7]$.

To save energy and reduce costs, an alternative desulfurization process needs to be developed. In thiophenic compound removal, advanced oxidation processes, which begin with oxygen radicals, may take 3 forms: chemical, bio-, and photooxidation [8-10]. The great advantage of photocatalytic removal compared to the previous two processes is that it occurs under ambient temperature and pressure, so after a reasonable time, an acceptable amount of pollutant is eliminated $[6,10]$.

When a semiconductor is irradiated by a light beam with energy equal or greater than its band gap, it can act as a photocatalyst $[6,8,9]$. In this case, an electron is transferred from the valence band to the conduction band. This transmission creates an electron in conduction band and a hole with positive charge in the valence band $[8,9,11,12]$. These electrons and holes can be transferred to the catalyst surface and begin redox reactions $[8,9,11]$.

Recombination of electrons and generated holes is considered as the most important factor limiting semiconductors' photocatalytic power $[5,9,10]$. In this case, the stimulated electron returns to the valence band without entering into reaction with the adsorbed component on the surface of the semiconductor and releases its energy 
as light or heat $[9,11]$. Normally, only $1 \%$ of electrons and generated holes participate in photocatalytic reaction, and the rest may be recombined without participating in the reaction [13].

Due to efficiency and the feasibility of conducting photocatalytic reactions at ambient conditions, and no need for hydrogen, research studies on the use of photocatalysts in order to remove sulfur compounds are increasing. Given the significance of sulfur removal from fuels and the important role of photo catalysts in the process efficiency, it seems very necessary to find a way to increase removal process efficiency. There are various methods for increasing photocatalytic strength and reducing recombination rate. Some methods increase photocatalytic power by improving structural properties, such as increasing the surface area and porosity, while some others increase the potential to remove contaminants by chemical modification and addition of another component to semiconductor structure $[5,7,9-11]$. One way to increase efficiency is to perform a photocatalytic process using carbon nanotubes and combine it with semiconductor [5, 9, 14-19].

$\mathrm{Vu}$ et al. indicated that addition of nanotubes to titania reduces the possibility of electron and hole recombination, and combination of titania with nanotubes with a ratio of $20: 1$ has more photocatalytic power than raw titania. In this study, after $8 \mathrm{~h}$ of irradiation by ultraviolet lamp $(250 \mathrm{~W})$, $80 \%$ DBT removal was achieved [5].

Given that very few research studies are conducted on the use of nanotubes to increase the efficiency of photocatalytic removal of thiophenic compounds based on studies done so far, the aim of this study is to evaluate the effect of important factors on removal of BT and DBT, as sample compounds with low reactivity, by using MWCNT-titania composite.

Today, with the advancement of computer science, design and optimization have become common ways of research development. Thus, many studies have been conducted for optimization of photocatalytic construction using different methods of experimental design. Thus, in this research, CCD method is applied to optimize photocatalyst construction condition.

\section{Materials and Methods}

2.1. Photocatalyst Synthesis for Optimization of MWCNT: Titania Ratio in Sol. The composites are made using sol-gel method and ratios that were optimized in our previous research [20]. Tetraethyl orthotitanate (95\%, Merck) was dissolved in isopropanol (obtained from Chemical Industry Co. of Dr. Mojalali IR) with molar ratio of $1: 70$. In order to stabilize $\mathrm{pH}$ level, the required amount of nitric acid (65\%, Merck) solution with $\mathrm{pH}=3$ was added, and the mixture was stirred for $1 \mathrm{~h}$ using a magnetic stirrer during the sol preparation. Thereafter, MWCNT (RIPI, $\mathrm{D}=10-20 \mathrm{~nm}$ ) was added to the mixture and was stirred for another $3 \mathrm{~h}$. The nanotube ratio was selected in such a way that the mass ratio of MWCNT to titania in the resultant composite will be equal to $0.65,1,1.3$, and 2.6. The samples were then labeled as samples 1-4 (S1, S2, S3, and S4).
After this step, until when the gel is formed and dried, the obtained mixture was kept at room temperature. Then, the samples were placed in a furnace and heated at $5^{\circ} \mathrm{C} / \mathrm{min}$ to reach $450^{\circ} \mathrm{C}$. The samples were calcined for $1 \mathrm{~h}$ at this temperature. Then, they were cooled down at room temperature with the same rate.

2.2. Photocatalyst Synthesis for CCD Optimization. In this part of the research, MWCNT to titania ratio was constant and equal to the best ratio based on the previous section result, but we used different $\mathrm{pH}$ values $(2,2.4,3,3.6$ and 4) for sol preparation. Also, proper amounts of p-25 (Degussa, $\mathrm{BET}=50 \mathrm{~m}^{2} / \mathrm{g}$, band gap $=3.4 \mathrm{ev}$ ) were added to the sol exactly after MWCNT addition and stirred for $3 \mathrm{~h}$. This solution was kept at room temperature. After solvent evaporation, the samples were calcinated at different temperatures $\left(300,361,450,539\right.$, and $\left.600^{\circ} \mathrm{C}\right)$. The heating and cooling rates were the same as in the previous section.

2.3. Test Method and Concentration Measurement. To assess photocatalytic power of the particles, $0.5 \mathrm{~g}$ of the catalyst was added to $100 \mathrm{ml}$ of n-hexane (95\%, Dr. Mojalali IR) solution with initial concentration of DBT (100\%, Merck) or BT (100\%, Merck) equal to $200 \mathrm{ppm}$. Then, the liquid was stirred in the dark until adsorption equilibrium is established. In this case, the solution's equilibrium concentration was considered as the initial concentration for the next step.

In the next step, $1 \mathrm{mM}$ of hydrogen peroxide (30\%, Merck), as an oxidizing agent, was added to the mixture. Then, it was exposed to UV lamp (UVC, Philips, 9W) in a mirror box for $20 \mathrm{~min}$. In order to measure concentration, samples were taken at each stage and photocatalyst was separated from the sample by centrifugation. Then, concentration was calculated by measuring absorption using a UV spectrophotometer.

2.4. Experimental Design and Statistical Analysis. In order to achieve desired results, there are various methods of experimental design which reduce the number of tests, determine the effects of the studied parameters on the target function, and ultimately specify the optimum conditions. In the current research, CCD, which is the most widely used RSM (response surface method), is applied to optimize BT and DBT removal.

There are many parameters that can affect the photocatalytic power of composites. But in this study, calcination temperature, sol $\mathrm{pH}$, and $\mathrm{p}-25$ to nanotubes ratio were considered as important parameters in determining the photocatalytic power of this structure. The rest of the conditions are assumed to be fixed in all experiments.

The photocatalytic removal rate of thiophenic compounds is defined as the system response and target parameter. Equation 1 is used for its calculation, where $C_{t}$ is final concentration and $C_{0}$ is initial concentration (the obtained value after absorption equilibrium).

$$
y=100 \times\left(\frac{C_{0}-C_{t}}{C_{0}}\right) .
$$


TABLE 1: Actual and coded values of independent variables.

\begin{tabular}{lccccc}
\hline Factor & \multicolumn{5}{c}{ Level } \\
& -1.68 & -1 & 0 & 1 & 1.68 \\
\hline$\alpha:$ Temp $\left({ }^{\circ} \mathrm{C}\right)$ & 300 & 361 & 450 & 539 & 600 \\
$\beta: \mathrm{pH}$ & 2 & 2.4 & 3 & 3.6 & 4 \\
$\gamma: \mathrm{p}-25:$ MWCNT ratio $(\mathrm{g} / \mathrm{g})$ & 0 & 1 & 2.5 & 4 & 5 \\
\hline
\end{tabular}

TABLE 2: Different experiment conditions and their response values.

\begin{tabular}{lccccc}
\hline & \multicolumn{3}{c}{ Factor } & \multicolumn{2}{c}{ \% removal } \\
Experiment number & $\alpha$ & $\beta$ & $\gamma$ & BT & DBT \\
\hline 1 & 361 & 2.4 & 1 & 25 & 88.5 \\
2 & 539 & 2.4 & 1 & 8.4 & 21.6 \\
3 & 361 & 3.6 & 1 & 29.4 & 82.5 \\
4 & 539 & 3.6 & 1 & 9.5 & 29.1 \\
5 & 361 & 2.4 & 4 & 26.4 & 90.6 \\
6 & 539 & 2.4 & 4 & 9.4 & 42 \\
7 & 361 & 3.6 & 4 & 35.8 & 93.2 \\
8 & 539 & 3.6 & 4 & 15.7 & 55.7 \\
9 & 300 & 3 & 2.5 & 37.3 & 90.4 \\
10 & 600 & 3 & 2.5 & 8.9 & 21.7 \\
11 & 450 & 2 & 2.5 & 10.9 & 68.3 \\
12 & 450 & 4 & 2.5 & 11.9 & 66.5 \\
13 & 450 & 3 & 0 & 13.7 & 41.9 \\
14 & 450 & 3 & 5 & 23.5 & 62 \\
15 & 450 & 3 & 2.5 & 11.3 & 60 \\
16 & 450 & 3 & 2.5 & 10.2 & 55.2 \\
17 & 450 & 3 & 2.5 & 14.8 & 53.6 \\
18 & 450 & 3 & 2.5 & 10.9 & 55 \\
\hline
\end{tabular}

Ranges of change for every variable are determined based on previous studies and preliminary tests. Accordingly, temperature between $300^{\circ} \mathrm{C}$ (the temperature required for the formation of anatase phase) and $600^{\circ} \mathrm{C}$ (the nanotube burns at higher temperatures) [5], $\mathrm{pH}$ between 2 and 4 (due to the absence of gel formation in nonacidic $\mathrm{pH}$ [21]), $\mathrm{p}-25$ to nanotube ratio between 0 and 5 (composite cannot be stimulated with visible light at higher ratios.) were considered. Thus, actual and coded values of every parameter are shown in Table 1.

Experiments are designed according to five levels of CCD. A design with these conditions and four replicas at center point includes 18 tests according to Table 2 .

Data analysis was performed using design expert v.7 software, and the quadratic model was used to predict the parameters' behavior. The accuracy of a model can be assessed in different ways. One of the parameters used in this field was to compare the values obtained experimentally with values predicted by the model.

Also, in order to evaluate the parameters' effect and model validity, $R^{2}, F$ value, $p$ value, and main effects chart are employed. Of course, to assess the model accuracy, $R^{2}$ should not be considered as the only comparison criteria,

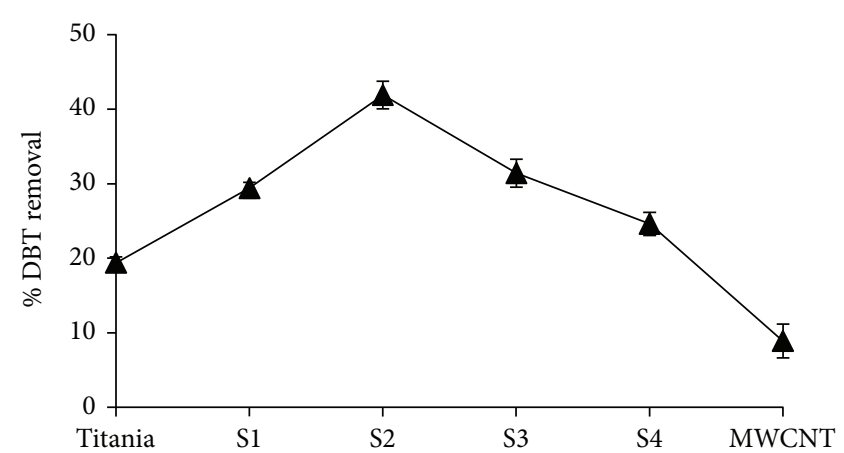

FIgURE 1: \% DBT removal using composites with different MWCNT : titania ratio.

because it can be increased by adding a number of factors (even noninfluential factors); to do so, adjusted $R^{2}$ and proximity of these two values to each other should be employed, as well.

\section{Results}

3.1. Influence of MWCNT: Titania Ratio on Photooxidation of DBT. Figure 1 indicates percentage DBT removed versus photocatalyst with different MWCNT : titania ratio. For better understanding, results using MWCNT alone and using photocatalyst without MWCNT addition were also shown. MWCNT has photocatalytic potential, and its addition to composite increases photocatalytic power. This increment can be explained as a result of reduction in the possibility of electron and hole recombination. However, higher ratios may lead to light scattering in solution; though, they may inversely affect photocatalytic removal rate $[5,7,16,19]$. Therefore, the optimum sample is $\mathrm{S} 2$ with mass ratio of MWCNT : titania equal to 1 .

3.2. ANOVA. The 18 suggested experiments were performed under specified conditions, and BT and DBT removal results are shown in Table 2. The results were analyzed using ANOVA test. Equation 2 is the model that is proposed to predict BT and DBT removal. Coefficients of this equation are listed in Table 3. $\alpha, \beta$, and $\gamma$ are main factors (listed in Table 1) in actual value.

$$
\begin{aligned}
\text { \%removal }= & A+B \times \alpha+C \times \beta+D \times \gamma+E \times \alpha \\
& \times \beta+F \times \alpha \times \gamma+G \times \beta \times \gamma+H \\
& \times \alpha^{2}+I \times \beta^{2}+J \times \gamma^{2} .
\end{aligned}
$$

$R^{2}, F$ value, and $p$ value are given in Table 4 . For both thiophenic compounds, high $F$ value and $p$ value $<0.05$ indicate that the model is significant. In both cases, nonsignificant lack of fit means the model is properly fitted to the data $[22,23] . R^{2}$ values $>0.95$ means that the model properly predicts parameters' changes (in the studied range) and, in both cases, under $5 \%$ of total changes cannot be explained by the model [24] which can also be confirmed by proximity of $R^{2}$ and adjusted $R^{2}$ [22-24]. Figure 2 presents predicted values versus obtained values from the experiments, where 
TABle 3: Coefficients of (2).

\begin{tabular}{lcc}
\hline Coefficient & BT & Pollutant \\
\hline$A$ & 160.75 & DBT \\
$B$ & -0.55133 & 437.364 \\
$C$ & 1.47975 & -0.6270 \\
$D$ & -8.75249 & -113.8877 \\
$E$ & -0.015085 & -14.9496 \\
$F$ & -0.0005606 & 0.05798 \\
$G$ & 1.42952 & 0.031954 \\
$H$ & 0.0005537 & 2.07421 \\
$I$ & 0.75875 & 0.00012 \\
$J$ & 0.12506 & 14.07153 \\
\hline
\end{tabular}

proximity of points to lines suggests little difference between predicted and obtained values $[23,24]$.

In addition, $p$ values for the given parameters and their interaction are shown in Table 4. According to this table, $\alpha$, $\beta$, and $\gamma$ are 3 significant factors in BT removal, while only $\alpha$ and $\gamma$ and their interaction are significant in DBT removal. Among these factors, temperature is most effective in both BT and DBT removal. According to the main effect graph, shown in Figure 3, the same result is obtained because temperature changes lead to $30 \%$ change in BT response and $80 \%$ change in DBT response.

Response surface plot, shown in Figure 4, indicates simultaneous effects of $\alpha$ and $\gamma$ (when the third parameter is at the central point) on the DBTs' response.

According to the obtained results, the structure of photocatalytic strength decreases with increasing temperature. It has been demonstrated that by increasing the calcination temperature or calcination time, crystalline particles grow in size which results in decreased specific surface of the structure [3]. Decreased specific surface of the structure indicates reduction of active sites for the reaction. On the other hand, rising temperature converts anatase phase to rutile and therefore reduces photocatalytic power. For this reason, at high temperatures, positive impact of more amount of p-25 on the structure is obvious.

3.3. Optimization and Confirmation. In this process, optimization means obtaining a structure which results in the highest rate of BT and DBT removal. Based on the performed analysis, a structure which is made at $\mathrm{pH}=4$ with $\mathrm{p}-25$ five times more than carbon nanotube that is calcined at $300^{\circ} \mathrm{C}$ can be an optimal structure. The model predicts that employing this structure may result in $100 \%$ DBT removal and $60.38 \%$ BT removal. This sample was synthesized, and within 20 minutes (average of four iterations), all DBT and $59.8 \%$ of BT were removed. Proximity of the obtained and predicted values by the model indicates suitability of the test design and the proposed model.

3.4. Characterization of the Optimized Sample. The result of XRD test (tube Co, $\lambda=1.78897 \AA$, step size $=0.02^{\circ} / \mathrm{s}$ ) on the optimized sample is shown in Figure 5. Anatase diffraction peaks was found at $25.1,38.5,47.8$, and $70.2^{\circ}$ corresponding to the reflections from 101, 112, 200, and 116 crystal planes $[5,7,14-17,25]$. The peaks at $27.6,40$, 41,44 , and $85.8^{\circ}$ are the diffractions of rutile $110,200,111$, 210 , and $400[14,25]$. Nanotube (002) peak appears at $25.8^{\circ}$ $[18,19]$ which is usually combined with anatase phase and cannot be specified separately.

Nanotube 100,004 , and 110 peaks appear at $42.2,52$, and $78^{\circ}[16-19]$. Brookite titania [26] or hydrate titania [27] peaks at 59.2 and 60.6 may be due to titania and acid presence in the sol. Accordingly, the produced titania is a combination of anatase and rutile. However, the observed rutile phase cannot be inferred as a result of anatase to rutile conversion at this temperature, yet it is because of a large amount of p-25 in the structure, so the resulting graph is actually similar to the p-25 graph to which nanotube peaks are added.

Using Scherrer equation (3), the size of the crystal is calculated $[2,17]$.

$$
D=\frac{k \lambda}{\beta \cos \theta},
$$

where $D$ is crystal diameter, $k$ is a shape factor equal to $0.94, \lambda$ is $\mathrm{X}$-ray wavelength equal to 1.79 Angstrom, $\theta$ is maximum peak angle, and $\beta$ is bandwidth at half height of the graph's maximum peak. Considering Figure 4 and Scherrer equation, the particles' size is $36 \mathrm{~nm}$. It is proved that adding nanotubes to the compound reduces the size of crystals when compared to raw titania and p-25 $[14,17]$.

Figure 6 shows light absorption of the optimized sample. To better compare the graphs, $\mathrm{p}-25$ light absorption is also included in Figure 6. All attempts made to improve structural properties of the photocatalysts are to produce a catalyst which can be stimulated by visible light irradiation.

As shown in the figure, due to the high amount of p-25 in the combination, the band gap of the optimized sample is equal to p-25. However, compared with p-25, the sample absorbs light of the visible region, as well [7, 14-17, 19]. When combined with titania, nanotube creates an energy level under titania conducting band. Therefore, electron can also be stimulated when irradiated with visible light and moves between nanotubes and titania. It should be noted that extending the absorption edge of $\mathrm{TiO}_{2}$ to the visible region is considered as one of the main objectives to have active photocatalyst in the visible light region $[7,10,14,15,17]$.

\subsection{Photolysis, Oxidation, and Photooxidation Comparison.}

The decrease in the concentration of BT and DBT under different conditions is presented in Table 5. According to the results, the photolysis process does not have the power to eliminate thiophene. The catalyst, by itself, induces a slight decrease in concentrations by adsorption. However, when catalyst and light are used, in addition to adsorption, oxidation also occurs, and it is evident that, when ultraviolet light is used due to more emitted energy, the electron and hole production rate increases, and therefore, the amount of removal is higher than the use of visible light. Hydrogen peroxide is not capable of oxidizing BT but oxidizes DBT to 
TABLE 4: ANOVA results for quadratic model of BT and DBT photooxidation.

\begin{tabular}{|c|c|c|c|c|c|c|}
\hline & Mean square & $F$ value & $p$ value (BT) & Mean square & $F$ value & $p$ value (DBT) \\
\hline Model & 168.16 & 28.11 & $<0.0001$ & 982.27 & 37.24 & $<0.0001$ \\
\hline$\alpha($ Temp) & 1078.50 & 180.27 & $<0.0001$ & 7589.22 & 287.72 & $<0.0001$ \\
\hline$\beta(\mathrm{pH})$ & 38.34 & 6.41 & 0.0352 & 15.98 & 0.61 & 0.4588 \\
\hline$\gamma(\mathrm{p}-25)$ & 72.57 & 12.13 & 0.0083 & 641.56 & 24.32 & 0.0011 \\
\hline$\alpha \beta$ & 5.12 & 0.86 & 0.3820 & 75.65 & 2.87 & 0.1288 \\
\hline$\alpha \gamma$ & 0.045 & 0.0075 & 0.9330 & 146.21 & 5.54 & 0.0464 \\
\hline$\beta \gamma$ & 13 & 2.17 & 0.1786 & 27.38 & 1.04 & 0.3381 \\
\hline$\alpha^{2}$ & 245.43 & 41.02 & 0.0002 & 11.71 & 0.44 & 0.5240 \\
\hline$\beta^{2}$ & 0.91 & 0.15 & 0.7067 & 313.08 & 11.87 & 0.0088 \\
\hline$\gamma^{2}$ & 100.15 & 16.74 & 0.0035 & 3.00 & 0.11 & 0.7444 \\
\hline Lack of fit & 7.05 & 1.68 & 0.356 & 37.53 & 4.81 & 0.1131 \\
\hline$R^{2}$ & & & 0.9693 & & & 0.9767 \\
\hline $\operatorname{Adj} R^{2}$ & & & 0.9349 & & & 0.9505 \\
\hline
\end{tabular}
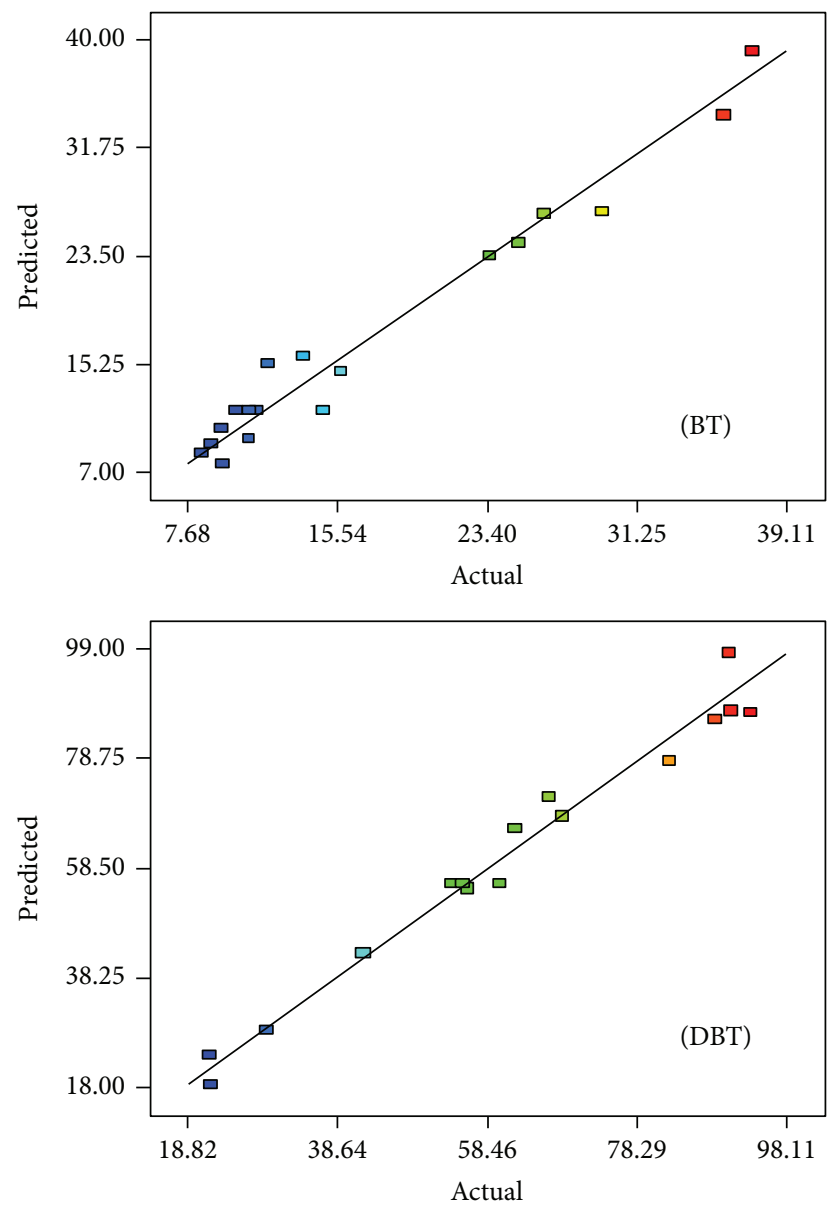

FIGURE 2: Predicted versus actual values for photooxidation of BT and DBT.

a small extent, and when solution is exposed to light, its oxidation power is slightly increased and, under ultraviolet light, it can also reduce the concentration of BT, but it is not significant at all. When the catalyst and hydrogen peroxide are added to the solution (chemical oxidation), a significant change in concentrations occurs. As shown in the table, there is a reduction of $29.3 \%$ in the concentration of $\mathrm{BT}$ and $86 \%$ reduction in the concentrations of DBT after $20 \mathrm{~min}$. This synergistic effect shows that in this case, the catalyst acts as an active site and increases the contact surface of hydrogen peroxide and thiophenes. If light is also added to this system, chemical oxidation becomes photooxidation, and the power of thiophene removal is increased. Based on the results obtained, the catalyst with visible light is also excited, and its removal ability is more than chemical oxidation (especially in the case of BT).

3.6. Kinetics of Photooxidation. When it became obvious that samples can absorb visible light, some tests were conducted using visible light for BT and DBT removal. The results showed that visible light can help in achieving total removal of DBT and $42 \%$ removal of BT. BT and DBT removal reactions can be regarded as a first-order equation $[2-4,6]$, in which reaction rate constants of $\mathrm{BT}$ and DBT removal rate are 0.953 and $7.981 / \mathrm{h}$, respectively. For better comparison of results obtained, constant values obtained for BT and DBT removal rate in previous studies are listed in Table 6. Comparison of data in Table 6 shows dramatic increase of removal rate in the current research due to the addition of nanotube to titania. There is also an important difference between the current and previous research results; in this study, visible light is used, while the results presented in Table 6 were obtained with ultraviolet light.

\section{Conclusion}

In order to achieve maximum thiophenic compound removal rate, construction condition of titania-nanotube composite is optimized at $300^{\circ} \mathrm{C}, \mathrm{pH}=4$, and titaniananotube ratio equal to 5 . The results showed that, added to increasing photocatalytic power, addition of nanotubes to the system stimulates the structure with visible light. Moreover, DBT removal is far easier than BT removal, because the optimized structure can completely remove 

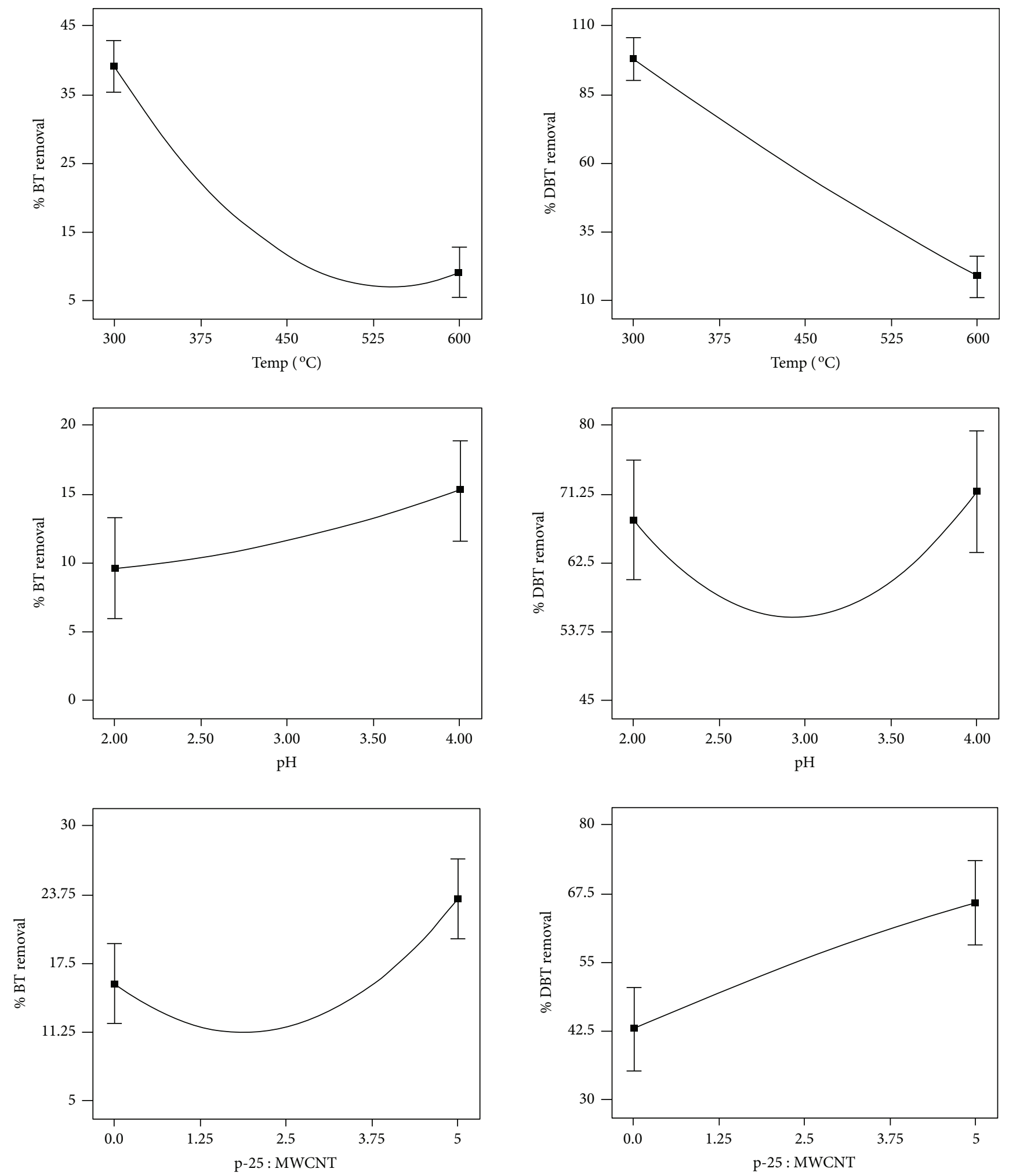

FIgUre 3: Main effect plots for the photooxidation of BT and DBT.

DBT within 20 min (both with ultraviolet light and with visible light); but changing ultraviolet to visible light in case of BT reduces its removal rate from 59.8 to $42 \%$. Reaction rate constant of DBT and $\mathrm{BT}$ removal rate in a first-order equation are 7.98 and $0.9531 / \mathrm{h}$, respectively. These values are several times more than those obtained by previous researchers; the increase was caused principally by adding nanotube to the composite structure. 


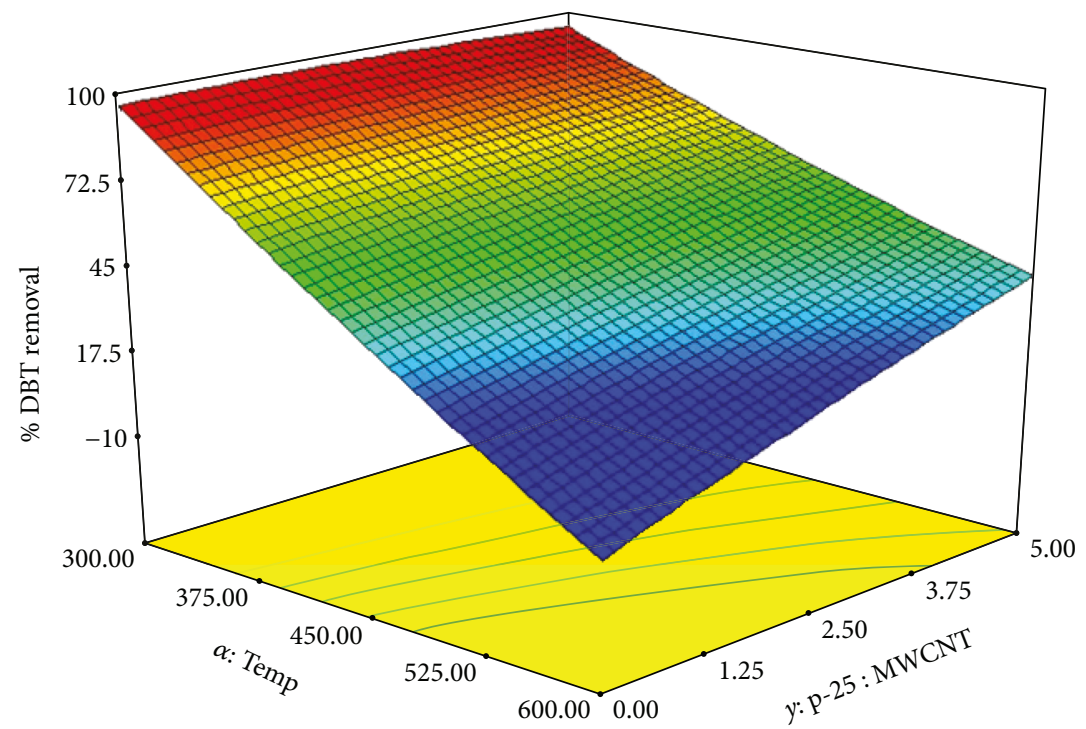

FIGURE 4: Contour plot for the degradation of DBT indicating the effect of interaction between temperature and p-25:MWCNT.

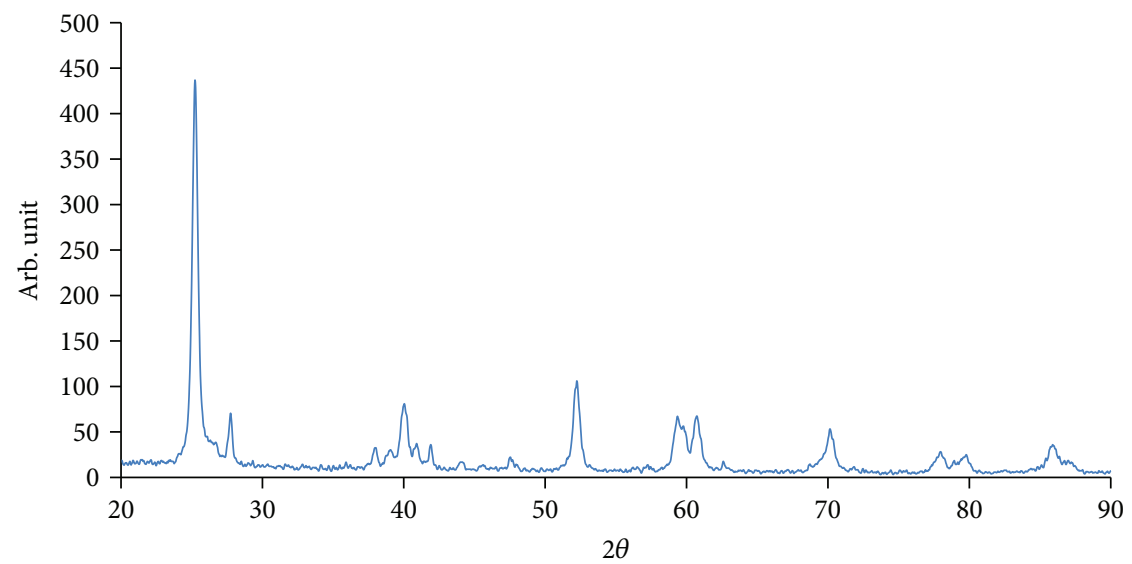

FIGURE 5: XRD pattern of optimum sample.

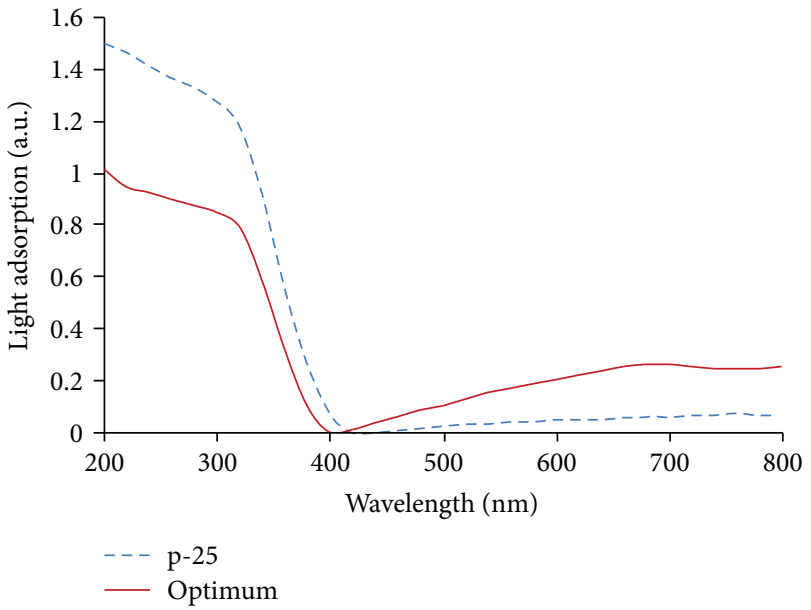

(a)

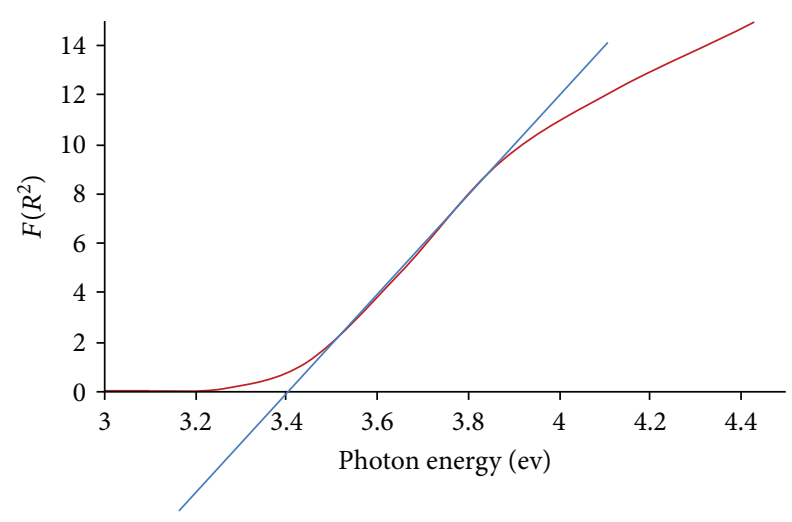

(b)

FIgURE 6: UV-Vis diffuse reflectance spectra of p-25 and optimum sample. 
TABLE 5: \% BT and DBT removal in different condition after 20 min.

\begin{tabular}{lcc}
\hline Factor & \% BT removal & \% DBT removal \\
\hline UV light & - & - \\
Visible light & - & - \\
Catalyst & 2.6 & 9.8 \\
Catalyst + UV light & 9.5 & 14.2 \\
Catalyst + visible light & 6.4 & 11.9 \\
$\mathrm{H}_{2} \mathrm{O}_{2}$ & - & 2.0 \\
$\mathrm{H}_{2} \mathrm{O}_{2}+\mathrm{UV}$ light & 1.3 & 4.4 \\
$\mathrm{H}_{2} \mathrm{O}_{2}+$ visible light & - & 3.3 \\
Catalyst $+\mathrm{H}_{2} \mathrm{O}_{2}$ & 29.3 & 86 \\
Catalyst $+\mathrm{H}_{2} \mathrm{O}_{2}+\mathrm{UV}$ light & 59.8 & 100 \\
Catalyst $+\mathrm{H}_{2} \mathrm{O}_{2}+$ visible & 42 & 100 \\
\hline
\end{tabular}

TABLE 6: Reaction rate constant in different researches.

\begin{tabular}{lcccc}
\hline Reference & Year & Catalyst & $K_{\mathrm{BT}}(1 / \mathrm{h})$ & $K_{\mathrm{DBT}}(1 / \mathrm{h})$ \\
\hline$[4]$ & 2002 & $\mathrm{p}-25$ & & 0.035 \\
{$[2]$} & 2006 & $\mathrm{TiO}_{2}$ & & 0.9 \\
{$[1]$} & 2008 & $\mathrm{TiO}_{2}$ & & 0.9 \\
{$[28]$} & 2008 & $\mathrm{p}-25$ & & 0.6 \\
{$[29]$} & 2009 & $\mathrm{TS}-1$ & & 0.48 \\
{$[30]$} & 2010 & $\mathrm{TS}-1$ & & 0.48 \\
{$[6]$} & 2014 & $\mathrm{TiO}_{2}$ & 0.38 & 0.79 \\
This research & & $\mathrm{TiO}_{2}+\mathrm{MWCNT}$ & 0.953 & 7.98 \\
\hline
\end{tabular}

\section{Conflicts of Interest}

The authors declare that they have no conflicts of interest.

\section{Acknowledgments}

The researchers of the current study wish to thank Degussa Iran Co. for providing p-25 titania free of charge.

\section{References}

[1] F. T. Li, R. H. Liu, Z. M. Sun, and D. S. Zhao, "Photocatalytic oxidation kinetics of thiophene with nano- $\mathrm{TiO}_{2}$ as photocatalyst," in 2008 2nd International Conference on Bioinformatics and Biomedical Engineering, Shanghai, China, 2008.

[2] J. Robertson and T. J. Bandosz, "Photooxidation of dibenzothiophene on $\mathrm{TiO}_{2}$ /hectorite thin films layered catalyst," Journal of Colloid and Interface Science, vol. 299, no. 1, pp. 125-135, 2006.

[3] Z. Hasan, J. Jeon, and S. H. Jhung, "Oxidative desulfurization of benzothiophene and thiophene with $\mathrm{WO}_{\mathrm{x}} / \mathrm{ZrO}_{2}$ catalysts: effect of calcination temperature of catalysts," Journal of Hazardous Materials, vol. 205-206, pp. 216-221, 2012.

[4] S. Matsuzawa, J. Tanaka, S. Sato, and T. Ibusuki, "Photocatalytic oxidation of dibenzothiophenes in acetonitrile using $\mathrm{TiO}_{2}$ : effect of hydrogen peroxide and ultrasound irradiation," Journal of Photochemistry and Photobiology A: Chemistry, vol. 149, no. 1-3, pp. 183-189, 2002.
[5] T. H. T. Vu, T. T. T. Nguyen, P. H. T. Nguyen et al., "Fabrication of photocatalytic composite of multi-walled carbon nanotubes/ $\mathrm{TiO}_{2}$ and its application for desulfurization of diesel," Materials Research Bulletin, vol. 47, no. 2, pp. 308-314, 2012.

[6] G. Dedual, M. J. MacDonald, A. Alshareef, Z. Wu, D. C. W. Tsang, and A. C. K. Yip, "Requirements for effective photocatalytic oxidative desulfurization of a thiophene-containing solution using $\mathrm{TiO}_{2}$," Journal of Environmental Chemical Engineering, vol. 2, no. 4, pp. 1947-1955, 2014.

[7] E. S. Aazam, "Visible light photocatalytic degradation of thiophene using $\mathrm{Ag}-\mathrm{TiO}_{2} /$ multi-walled carbon nanotubes nanocomposite," Ceramics International, vol. 40, no. 5, pp. 6705-6711, 2014.

[8] R. Munter, "Advanced oxidation process - current status and prospects," Proceedings of the Estonian Academy of Sciences Chemistry, vol. 50, no. 2, pp. 59-80, 2001.

[9] H. Park, Y. Park, W. Kim, and W. Choi, "Surface modification of $\mathrm{TiO}_{2}$ photocatalyst for environmental applications," Journal of Photochemistry and Photobiology C: Photochemistry Reviews, vol. 15, pp. 1-20, 2013.

[10] T. P. Dhanya and S. Sugunan, "Preparation, characterization and photocatalytic activity of $\mathrm{N}$ doped $\mathrm{TiO}_{2}$," IOSR Journal of Applied Chemistry, vol. 4, no. 3, pp. 27-33, 2013.

[11] M. Pelaez, N. T. Nolan, S. C. Pillai et al., "A review on the visible light active titanium dioxide photocatalysts for environmental applications," Applied Catalysis B: Environmental, vol. 125, pp. 331-349, 2012.

[12] V. Loryuenyong, K. Angamnuaysiri, J. Sukcharoenpong, and A. Suwannasri, "Sol-gel derived mesoporous titania nanoparticles: effects of calcination temperature and alcoholic solvent on the photocatalytic behavior," Ceramics International, vol. 38, no. 3, pp. 2233-2237, 2012.

[13] Y. P. Tsai, R. Doong, J. C. Yang, and Y. J. Wu, "Photo-reduction and adsorption in aqueous $\mathrm{Cr}(\mathrm{VI})$ solution by titanium dioxide, carbon nanotubes and their composite," Journal of Chemical Technology and Biotechnology, vol. 86, no. 7, pp. 949-956, 2011.

[14] H. Liu, X. Yu, and H. Yang, “The integrated photocatalytic removal of $\mathrm{SO}_{2}$ and $\mathrm{NO}$ using $\mathrm{Cu}$ doped titanium dioxide supported by multi-walled carbon nanotubes," Chemical Engineering Journal, vol. 243, pp. 465-472, 2014.

[15] H. Liu, H. Zhang, and H. Yang, "Photocatalytic removal of nitric oxide by multi-walled carbon nanotubes-supported $\mathrm{TiO}_{2}$," Chinese Journal of Catalysis, vol. 35 , no. 1, pp. 66-77, 2014.

[16] Y. Koo, G. Littlejohn, B. Collins et al., "Synthesis and characterization of $\mathrm{Ag}-\mathrm{TiO}_{2}-\mathrm{CNT}$ nanoparticle composites with high photocatalytic activity under artificial light," Composites Part B: Engineering, vol. 57, pp. 105-111, 2014.

[17] S. S. Mali, C. A. Betty, P. N. Bhosale, and P. S. Patil, "Synthesis, characterization of hydrothermally grown $\mathrm{MWCNT}-\mathrm{TiO}_{2}$ photoelectrodes and their visible light absorption properties," ECS Journal of Solid State Science and Technology, vol. 1, no. 2, pp. M15-M23, 2012.

[18] T. A. Saleh, M. A. Gondal, Q. A. Drmosh, Z. H. Yamani, and A. al-yamani, "Enhancement in photocatalytic activity for acetaldehyde removal by embedding $\mathrm{ZnO}$ nano particles on multiwall carbon nanotubes," Chemical Engineering Journal, vol. 166, no. 1, pp. 407-412, 2011.

[19] N. Hintsho, L. Petrik, A. Nechaev, S. Titinchi, and P. Ndungu, "Photo-catalytic activity of titanium dioxide carbon nanotube 
nano-composites modified with silver and palladium nanoparticles," Applied Catalysis B: Environmental, vol. 156-157, pp. 273-283, 2014.

[20] M. Barmala, A. Z. Moghadam, and M. R. Omidkhah, "Increased photo-catalytic removal of sulfur using titania/ MWCNT composite," Journal of Central South University, vol. 23, no. 5, pp. 1066-1070, 2016.

[21] M. E. Simonsen and E. G. Sogaard, "Sol-gel reactions of titanium alkoxides and water: influence of $\mathrm{pH}$ and alkoxy group on cluster formation and properties of the resulting products," Journal of Sol-Gel Science and Techology, vol. 53, no. 3, pp. 485-497, 2010.

[22] H. Hossini, M. Safari, R. Rezaee, R. D. C. Soltani, O. Giahi, and Y. Zandsalimi, "Application of experimental design approach for optimization of the photocatalytic degradation of humic substances in aqueous solution using immobilized $\mathrm{ZnO}$ nanoparticles," Journal of Advances in Environmental Health Research, vol. 3, no. 3, pp. 154-163, 2015.

[23] K. M. Lee and H. SBA, "Simple response surface methodology: investigation on advance photocatalytic oxidation of 4-chlorophenoxyacetic acid using UV-active $\mathrm{ZnO}$ photocatalyst," Maternité, vol. 8, no. 12, pp. 339-354, 2015.

[24] M. Antonopoulou, A. Giannakas, and I. Konstantinou, "Simultaneous photocatalytic reduction of $\mathrm{Cr}(\mathrm{VI})$ and oxidation of benzoic acid in aqueous N-F-codoped $\mathrm{TiO} 2$ suspensions: optimization and modeling using the response surface methodology," International Journal of Photoenergy, vol. 2012, Article ID 520123, 10 pages, 2012.

[25] F. J. Zhang, M. L. Chen, K. Zhang, and W. C. Oh, "Visible light photoelectrocatalytic properties of novel yttrium treated carbon nanotube/titania composite electrodes," Bulletin of the Korean Chemical Society, vol. 31, no. 1, pp. 133-139, 2010.

[26] O. A. al-Harbi, E. M. A. Hamzawy, and M. M. Khan, "Effect of different concentrations of titanium oxide $\left(\mathrm{TiO}_{2}\right)$ on the crystallization behavior of $\mathrm{Li}_{2} \mathrm{O}-\mathrm{Al}_{2} \mathrm{O}_{3}-\mathrm{SiO}_{2}$ glasses prepared from local raw materials," Journal of Applied Sciences, vol. 9, no. 16, pp. 2981-2986, 2009.

[27] X. Bin, Z. C. Yong, C. Bing, and F. H. Song, "Porous titanium treated by nitric acid with varied concentration and the bioactivity in vitro," Journal of Inorganic Materials, vol. 27, no. 5, pp. 555-560, 2012.

[28] N. A. Buang, F. Fadil, Z. A. Majid, and S. Shahir, "Characteristic of mild acid functionalized multiwalled carbon nanotubes towards high dispersion with low structural defects," Digest Journal of Nanomaterials and Biostructures, vol. 7, no. 1, pp. 33-39, 2012.

[29] D. Zhao, J. Zhang, J. Wang, W. Liang, and H. Li, "Photocatalytic oxidation desulfurization of diesel oil using Ticontaining zeolite," Petroleum Science and Technology, vol. 27, no. 1, pp. 1-11, 2009.

[30] Z. Juan, Z. Dishun, Y. Liyan, and L. Yongbo, "Photocatalytic oxidation dibenzothiophene using TS-1," Chemical Engineering Journal, vol. 156, no. 3, pp. 528-531, 2010. 

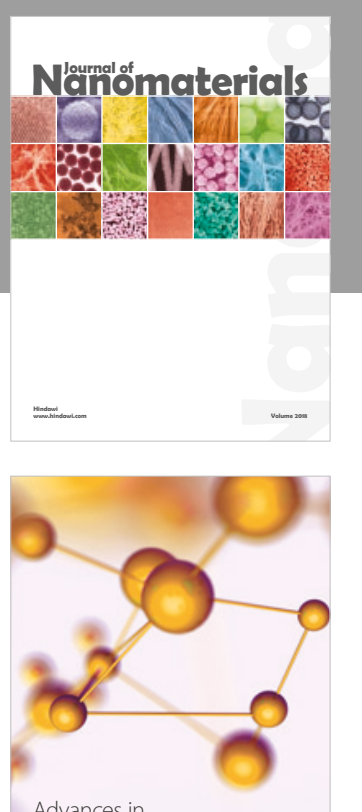

Physical Chemistry
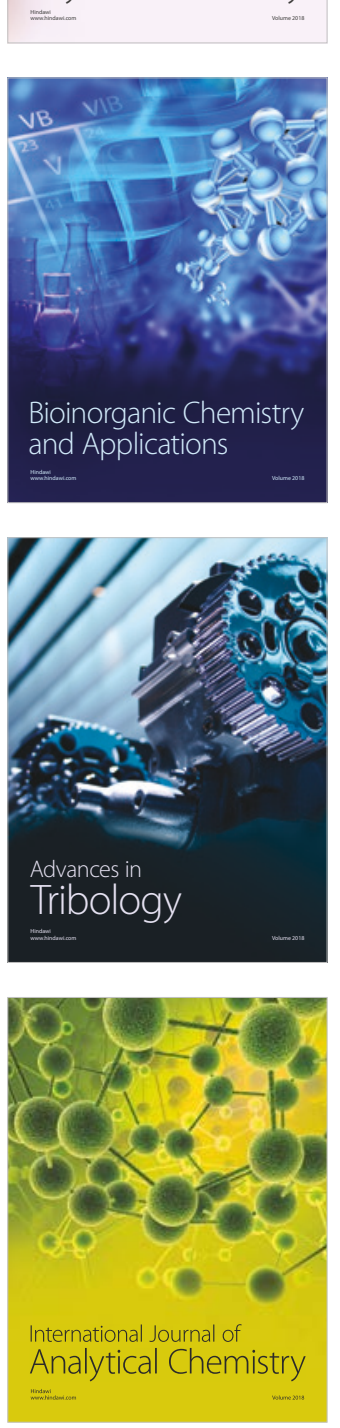

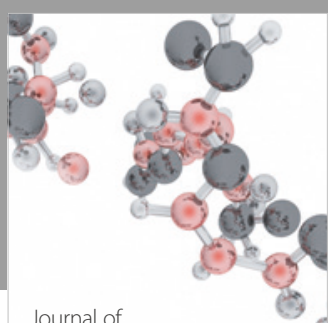

Analytical Methods

in Chemistry

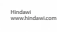

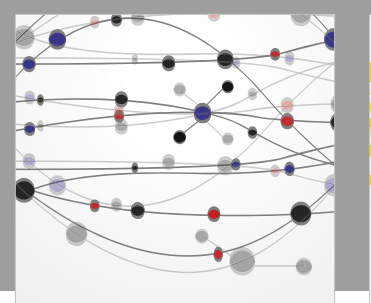

The Scientific World Journal

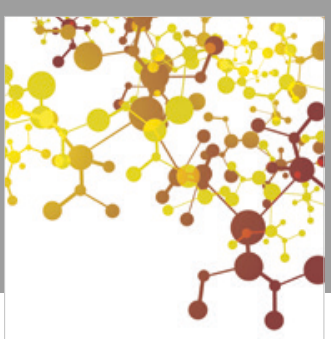

Journal of

Applied Chemistry
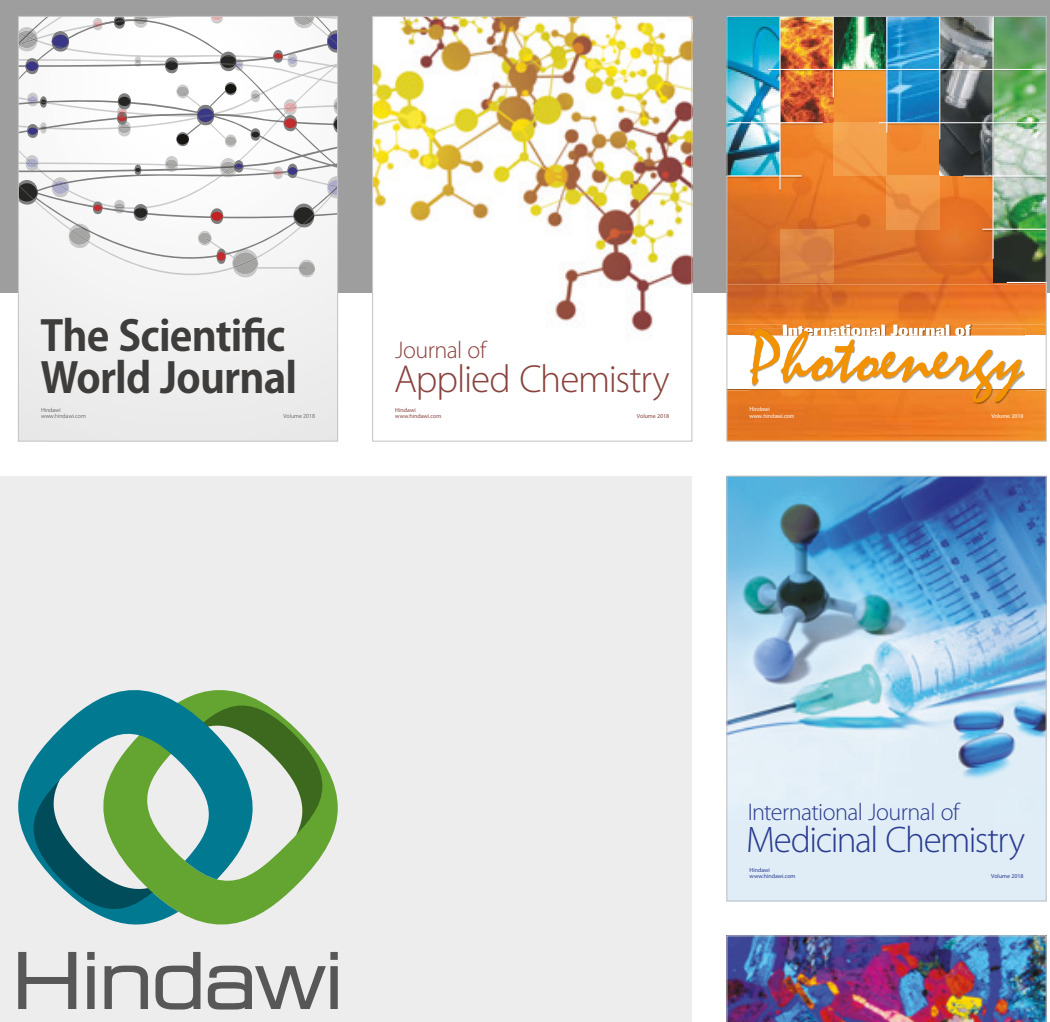

Submit your manuscripts at

www.hindawi.com
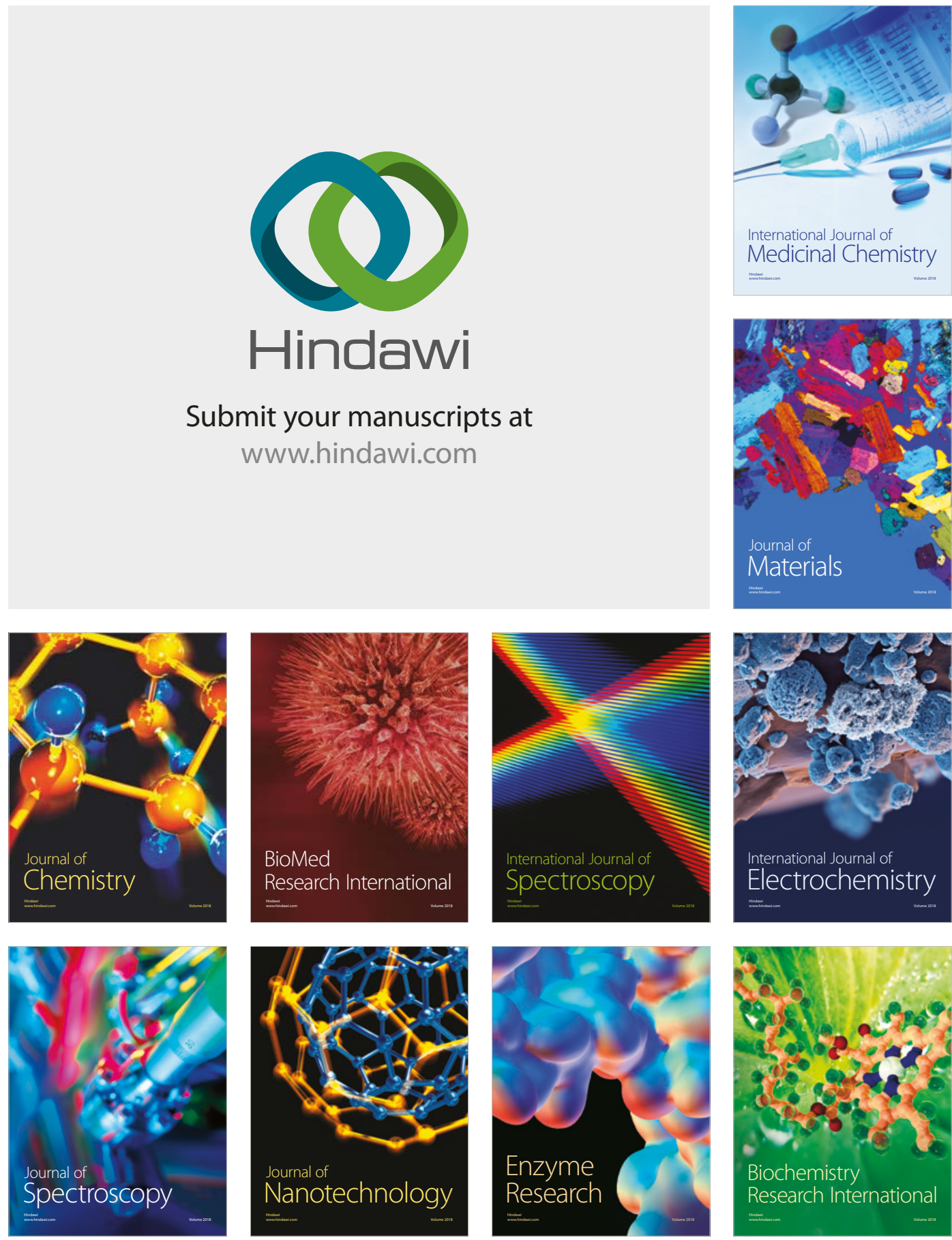
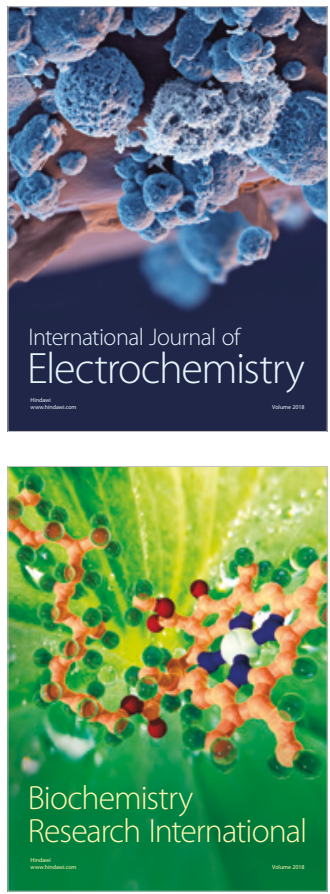